\title{
Analysis of the Causal Relationship of Body Image Factors in Patients with Cancer
}

\author{
Vita Ari Fatmawati ${ }^{1}$, Christantie Effendy ${ }^{2}$, Ridho Rahmadi ${ }^{*}$ \\ ${ }^{1}$ Master of Informatics Program \\ Faculty of Industrial Technology \\ Universitas Islam Indonesia \\ Yogyakarta, Indonesia \\ ${ }^{2}$ Department of Medical Surgical Nursing \\ Faculty of Medicine, Public Health and Nursing \\ Universitas Gadjah Mada \\ Yogyakarta, Indonesia \\ *ridho.rahmadi@uii.ac.id
}

\begin{abstract}
Patients with cancer can potentially experience the negative impacts of treatment. Physical conditions due to illness and therapy can affect the patient's body image. This study aims to find a causal model among body image factors of patients with cancer using the S3C-Latent Method. The measurement of body image of patients with cancer used the BIS questionnaire. One hundred and ninety-nine patients with cancer participated in this study. The results showed the existence of causal relationships between behavior to cognitive factors and duration of illness with reliability scores of 0.8 and 0.6 , respectively; from gender to affective factors, illness duration, behavior, and cognitive factors with reliability scores of $0.6,0.8,0.65$, and 1 , respectively. There are also causal relationships from age to affective factors, duration of illness, and cognitive factors with reliability scores of $0.8,0.7$, and 0.9 , respectively. The results also showed that affective factors are associated with behavior, cognitive factors, and duration of illness, with reliability scores of 1,1 , and 0.9 , respectively. The results showed further the association of cognitive factors and illness duration with a reliability score of 1 . We expect that the estimated causal model will serve as a scientific reference for medical experts in developing a better intervention such as treatment.
\end{abstract}

Keywords: cancer, body image, s3c-latent, causal relationship

Article info: submitted April 30, 2021, revised June 24, 2021, accepted July 11, 2021

\section{Introduction}

Health is among the most important factors in life. Various diseases can be a threat to humans, one of which is cancer. Cancer is caused by the abnormal growth of body cells as a result of mutations and changes in biochemical structure [1]. The International Agency for Research on Cancer (IARC) stated that the global cancer burden will increase by 19.3 million cases and 10 million deaths in 2020. New cancer cases in Indonesia in 2020 are around 396,914 people. Socioeconomic risk factors are the main factors driving the increase in cancer cases in the world.

Treatment in cancer patients can be divided into surgical (surgery) and systemic (chemotherapy, radiotherapy) [2]. Patients with cancer who receive surgical treatment are often faced with temporary or permanent effects that affect their appearance. The impact of treatment can be problems, such as scars or even loss of body parts due to amputation after surgery, sunburn from radiation therapy, and hair loss due to chemotherapy [3]. The patient's physical changes can affect the body image. Negative body image comes from negative thoughts and feelings which leads to decrease in the patient's self-esteem [4]. Body image is a primary factor of self-esteem.

Body image is a description of a person's assessment of physicality, satisfaction, and acceptance of the body. It can be interpreted as a form of estimation and evaluation of individuals on their bodies based on social norms and judgments from others [5]. Society places a high value on the beauty of the human body. Every individual has different perceptions about their own body, it is not uncommon for a person's perception to differ from the standards and expectations of society in general. Body image refers to a state in which a person perceives facts about their body, and whether they are satisfied or dissatisfied with their body. The level of individual satisfaction determines the level of self-confidence and self-esteem [6]. Measuring the body image of patients with cancer can be administered 
by using the BIS questionnaire. BIS was developed to measure body image in patients with cancer and it consists of 10 assessment items with five positive questions and five negative questions. The BIS test results showed a high reliability value (Cronbach's alpha 0.93 ). The body image of patients with cancer is influenced by three factors, i.e., affective, behavior, and cognitive [7].

Causal inference has been widely applied to draw causal conclusions based on observational studies, by providing non-randomized observational treatment [8]. Causal modeling is currently commonly used in the fields of bioinformatics, medicine, image processing, sports outcome prediction, risk analysis, and quantum nonlocality research [9]but where the ancestry of each copy mirrors that of the original. To every distribution of the observed variables that is compatible with the original causal structure, we assign a family of marginal distributions on certain subsets of the copies that are compatible with the inflated causal structure. It follows that compatibility constraints for the inflation can be translated into compatibility constraints for the original causal structure. Even if the constraints at the level of inflation are weak, such as observable statistical independences implied by disjoint causal ancestry, the translated constraints can be strong. We apply this method to derive new inequalities whose violation by a distribution witnesses that distribution's incompatibility with the causal structure (of which Bell inequalities and Pearl's instrumental inequality are prominent examples. In public health, causal inference has a central role [10], as it attempts to understand causal mechanisms underlying the system, which will be useful in developing intervention.

A causal model can be represented by a directed acyclic graph (DAG) or equivalently a structural equation model (SEM), and with a strong assumption, it can be used to describe the mechanisms that generated the observed data [11]. The causal models represent of the causal networks connecting exposure, effect, confounders, and other variables, that require explicit formulation of the relationships among these factors. As a result, causal models are a useful method for detecting graphically, identify potential causes of bias, and to advise investigators in the design of their data analysis [10].

Stable Specification Search for Cross-Sectional Data $(\mathrm{S} 3 \mathrm{C})$ is an exploratory causal approach that estimates causal models with observed variables. S3C combines a multi-objective optimization approach with stability selection concept to search for stable and parsimonious causal structures. There are two major sections of the S3C procedure. The first phase searches for relevant (stable and parsimonious) causal structures for the entire model complexities. The second part of S3C visualizes those relevant causal structures [12]. The extended version of $\mathrm{S} 3 \mathrm{C}$, that is, S3C-Latent, is developed to model causal relations among latent variables or factors. Latent variable models are commonly used in psychology, mental health studies, and other related areas [18].

\section{Methods}

This research is a quantitative study with an exploratory method using a cross sectional study design. The stages in this research include literature review, pre-processing data, causal modeling, evaluation, and dissemination. The research stages can be seen in Figure 1.

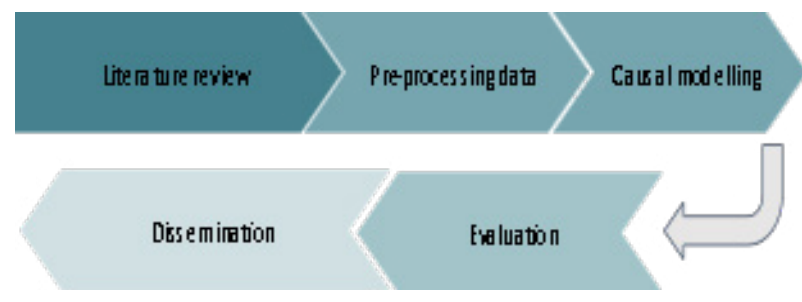

Figure 1. Research stages

\section{a. Literature review}

The research stage begins with a study of some relevant previous studies. Body image is a complex construct which describes how an individual views his/her physical appearance. Perceptions, thoughts, feelings, and behaviors about the entire body and its functions are of body image. Changes in body shape as a result of disease or treatment undergoing cancer patients can affect the body image. Treatment of patients with cancer has impact on both physical and psychological conditions [2]. Cancer patients undergoing chemotherapy experience decreased body health, body image disorders, sexual dysfunction, reduced social participation, and decreased work ability compared to the condition before chemotherapy [13].

Age, BMI, and various cancer treatments have been reported as potential risk factors for body image issues of patients with cancer [14]. Family support and marital status affect body image in post-mastectomy patients with cancer [4]. The physical condition of the patient after the mastectomy can reduce the patient's self-confidence. Family support can help patients to deal with self-concept problems. Married patients with breast cancer body image change after surgery, as the patients feel ashamed of their partners and have concern about the risks on their children, while unmarried patients tend to feel worried and ashamed of their physical condition, are afraid of being ostracized and are hard to find a mate.

$\mathrm{S} 3 \mathrm{C}$ is designed to model causal relationships between observed variables. S3C is an algorithm for determining causal relationships based on scores that aims to find stable specifications for robust cross-sectional data for a limited sample based on advances in stability selection using subsampling and selection algorithms. S3C combines a structure search process through SEM, NSGA-II, stability selection and visualization processes to present relevant relationships as a causal model. S3C extended to Stable Specification Search for Cross-Sectional Data for latent variables (S3C-Latent). S3C-Latent developed to model causal relationships among latent variables [12]. This study will use S3C-Latent to estimate causal relationships among factors representing the body image. 


\section{b. Pre-processing data}

The present study uses a dataset from previous study [15] with a span of data collection time in July 2017-February 2018. The dataset consists of 199 patients with cancer. Data collection tools in this study used a demographic data questionnaire and a Body Image Scale (BIS) questionnaire. BIS was developed to measure body image in patients with cancer. In collaboration with the European Organization for Research and Treatment of Cancer (EORTC) Quality of Life Study Group, a 10-item scale was constructed. BIS was tested in a heterogeneous population of 276 British cancer patients. The scale underwent a psychometric testing on 682 breast cancer patients from seven UK clinical trials based on the latest revision. The results of the BIS test showed a high reliability value (Cronbach's alpha 0.93).

Table 1. List of questions in BIS questionnaire

\begin{tabular}{|c|c|}
\hline Variables & Statement \\
\hline \multirow[t]{4}{*}{ Affective } & $\begin{array}{l}\text { 1. Have you been feeling self-conscious } \\
\text { about your appearance? }\end{array}$ \\
\hline & $\begin{array}{l}\text { 2. Have you felt less physically attractive as } \\
\text { a result of your disease or treatment? }\end{array}$ \\
\hline & $\begin{array}{l}\text { 3. Have you been dissatisfied with your } \\
\text { appearance when dressed? }\end{array}$ \\
\hline & $\begin{array}{l}\text { 4. Have you been feeling less feminine/ } \\
\text { masculine as a result of your disease or } \\
\text { treatment? }\end{array}$ \\
\hline \multirow[t]{3}{*}{ Behavior } & $\begin{array}{l}\text { 5. Did you find it difficult to look at } \\
\text { yourself naked? }\end{array}$ \\
\hline & $\begin{array}{l}\text { 6. Have you been feeling less sexually } \\
\text { attractive as a result of your disease or } \\
\text { treatment? }\end{array}$ \\
\hline & $\begin{array}{l}\text { 7. Did you avoid people because of the way } \\
\text { you felt about your appearance? }\end{array}$ \\
\hline \multirow[t]{3}{*}{ Cognitive } & $\begin{array}{l}\text { 8. Have you been feeling the treatment has } \\
\text { left your body less whole? }\end{array}$ \\
\hline & $\begin{array}{l}\text { 9. Have you felt dissatisfied with your } \\
\text { body? }\end{array}$ \\
\hline & $\begin{array}{l}\text { 10. Have you been dissatisfied with the } \\
\text { appearance of your scar? }\end{array}$ \\
\hline
\end{tabular}

BIS consists of 10 assessment items with five positive items and five negative items. BIS used a Likert scale, that is, four alternative answers ranging from the choice of "not at all" (0) to "very much" (3) [7]. The total score obtained from 0 to 30 can be calculated by adding up the scores of the 10 items. A higher score means a higher level of body image disturbance [16]. Body image factors of patients with cancer, are affective, behavior, and cognitive factors. Affective factors are indicated by assessment items 1-4, behavior factors by items $5-7$, and cognitive factors by items 8-10 [7].

This study uses demographic characteristics such as age, gender, education level, marital status, and duration of illness. Grouping the characteristics of the respondents is used to determine the distribution and percentage of each variable (see Table 2). Before the computation process, the dataset is checked for missing values, data distribution, data consistency or duplicate data in the dataset, and converted into a new format compatible for computations in $\mathrm{R}$ programming.

Table 2. Distribution of respondent characteristics

\begin{tabular}{|c|c|}
\hline $\begin{array}{c}\text { Respondent } \\
\text { characteristics }\end{array}$ & $\begin{array}{c}\text { Patients }(\mathrm{n}=199) \\
\mathrm{n}(\%)\end{array}$ \\
\hline \multicolumn{2}{|l|}{ Age } \\
\hline$<30$ & $4(2.0)$ \\
\hline $30-40$ & 27 (13.6) \\
\hline $41-50$ & $63(31.7)$ \\
\hline $51-60$ & $76(38.2)$ \\
\hline$>60$ & $29(14.6)$ \\
\hline \multicolumn{2}{|l|}{ Gender } \\
\hline Female & $183(92.0)$ \\
\hline Male & $16(8.0)$ \\
\hline \multicolumn{2}{|l|}{ Marital status } \\
\hline Married & $166(83.4)$ \\
\hline Not married & $31(15.6)$ \\
\hline Other & $2(1)$ \\
\hline \multicolumn{2}{|l|}{ Education level } \\
\hline No formal education & $20(10.1)$ \\
\hline Primary school & $90(45.2)$ \\
\hline Junior high school & $25(12.6)$ \\
\hline Senior high school & $40(20.1)$ \\
\hline Diploma & $7(3.5)$ \\
\hline Bachelor & $17(8.5)$ \\
\hline \multicolumn{2}{|l|}{ Duration of illness } \\
\hline$<3$ months & $17(8.5)$ \\
\hline 3-6 months & $61(30.7)$ \\
\hline 7-12 months & $56(28.1)$ \\
\hline 1-24 months & $22(11.1)$ \\
\hline$>24$ months & $43(21.6)$ \\
\hline
\end{tabular}

Table 2 summarizes information about demographic variables and medical characteristics among respondents. Almost $38,2 \%$ of the cancer patients were age 51-60, $92 \%$ are women, $83,4 \%$ were married. Most had attended primary school (45.2\%), and the most length of illness is between 3-6 months (30.7\%).

\section{c. Causal modeling}

Causal modeling aims to determine causal relationship among several variables. A causal model can be represented with a diagram of the relationships among independent, control, and dependent variables [17]. The observed variables represented by boxes, the unobserved/ latent variables by circles [18].

The computation in this study is conducted in parallel using a cluster computer with R v4.0.0 as language programming and R package, Stablespec. The CPU server 
equipped with 80 cores, 250 GB RAM, and 4 GPU, Jupyter GUI and console/terminal.

\section{1) Structural Equation Model}

S3C uses SEM to represent causal relationships. SEM is considered as the main language of causal modeling [19]. S3C-Latent employs SEM with latent variables which comprises a structural model and measurement model. The structural model for latent variables reads

\section{$\eta=B \eta+\Gamma \xi+\zeta$}

Where $\boldsymbol{\eta}$ is an $m \times 1$ vector for the endogenous latent (effect) variables, $\boldsymbol{\xi}$ is an $n \times 1$ vector for exogenous latent (cause) variables, $\boldsymbol{\zeta}$ is an $m \times 1$ vector for disturbance on $\boldsymbol{\eta}, \boldsymbol{B}$ is an $m \times m$ matrix for coefficients among $\boldsymbol{\eta}$ and $\Gamma$ is an $m \times n$ matrix for coefficient among $\boldsymbol{\xi}$. In addition, there are values $\boldsymbol{\Phi}$ and $\boldsymbol{\Psi}$ which represent the covariance matrix of $\boldsymbol{\xi}$ and $\boldsymbol{\zeta}$, respectively. It is assumed that $\mathrm{E}(\boldsymbol{\eta})=$ $\mathrm{E}(\boldsymbol{\xi})=\mathrm{E}(\boldsymbol{\zeta})=0, \boldsymbol{\xi}$ has no correlation with $\boldsymbol{\zeta}$ and $(\boldsymbol{I}-\boldsymbol{B})$ is non-singular.

The measurement model represents the effect from $\boldsymbol{\eta}$ to the observed variable, an $r \times 1$ vector $x$, and from $\zeta$ to the observed variable, a $q \times 1$ vector $y$. The measurements model reads

$$
x=\Lambda_{x} \xi+\delta
$$$$
\boldsymbol{y}=\Lambda_{y} \eta+\epsilon \text {, }
$$

where $r \times n$ matrix $\boldsymbol{\Lambda}_{x}$ and $q \times m$ matrix $\boldsymbol{\Lambda}_{y}$ contain the structural coefficients that connect the latent variables and indicators, the vectors $r \times 1$ vector $\boldsymbol{\delta}$ and $q \times 1$ vector $\epsilon$ contain errors value on the indicators. In addition, the $r \times r$ matrix $\boldsymbol{\Theta}_{\delta}$ and a $q \times q$ matrix $\boldsymbol{\Theta}_{\in}$ are the covariance matrices for $\boldsymbol{\delta}$ and $\boldsymbol{\epsilon}$. The indicator in $x$ and $y$ represent independent questionnaire items and assumed that no causal relation between them.

The next procedure is a model parameter estimation. The model parameters $\boldsymbol{\theta}$ comprises $\boldsymbol{B}, \boldsymbol{\Gamma}, \boldsymbol{\Lambda}_{x}, \boldsymbol{\Lambda}_{y,} \boldsymbol{\Phi}, \boldsymbol{\Psi}$, $\boldsymbol{\Theta}_{\delta}$, and $\boldsymbol{\Theta}_{\epsilon}$. SEM procedure estimates a model-implied covariance $\boldsymbol{\Sigma}(\boldsymbol{\theta})$ and assess how it close to covariance matrix $\boldsymbol{S}$. The covariance matrix $\boldsymbol{\Sigma}(\boldsymbol{\theta})$ for SEM with latent variables is a function of the model parameter $\boldsymbol{\theta}$ through

$$
\begin{aligned}
& \boldsymbol{\Sigma}(\boldsymbol{\theta})=\left[\begin{array}{ll}
\boldsymbol{\Sigma}_{y y}(\boldsymbol{\theta}) & \boldsymbol{\Sigma}_{y x}(\boldsymbol{\theta}) \\
\boldsymbol{\Sigma}_{x y}(\boldsymbol{\theta}) & \boldsymbol{\Sigma}_{x x}(\boldsymbol{\theta})
\end{array}\right] \\
& \boldsymbol{\Sigma}_{y y}(\boldsymbol{\theta})=\boldsymbol{\Lambda}_{y}(\boldsymbol{I}-\boldsymbol{B})^{-1}\left(\boldsymbol{\Gamma} \boldsymbol{\Phi} \boldsymbol{\Gamma}^{\prime}+\boldsymbol{\Psi}\right) \\
& {\left[(\boldsymbol{I}-\boldsymbol{B})^{-1}\right]^{\prime} \boldsymbol{\Lambda}_{\boldsymbol{y}}^{\prime}+\boldsymbol{\theta}_{\epsilon}} \\
& \boldsymbol{\Lambda}_{x} \boldsymbol{\Phi} \Gamma^{\prime}\left[(\boldsymbol{I}-\boldsymbol{B})^{-1}\right]^{\prime} \boldsymbol{\Lambda}_{y}^{\prime} \\
& \boldsymbol{\Sigma}_{x x}(\boldsymbol{\theta})=\boldsymbol{\Lambda}_{x} \boldsymbol{\Phi} \boldsymbol{\Lambda}_{x}^{\prime}+\boldsymbol{\Theta}_{\delta}
\end{aligned}
$$

where $\boldsymbol{\Sigma}_{y y}(\boldsymbol{\theta})$ is a covariance matrix of the indicator $\boldsymbol{y}$, $\boldsymbol{\Sigma}_{x y}(\boldsymbol{\theta})$ is a covariance matrix of the indicator $\boldsymbol{x}$ and $\boldsymbol{y}$, and $\boldsymbol{\Sigma}_{x x}^{x y}(\boldsymbol{\theta})$ as a covariance matrix of the indicator $\boldsymbol{x}$.
A DAG, and therefore SEM, has its corresponding Markov equivalence class or so called a partially completed DAG (CPDAG) [20]. This means that any distribution of probabilities entailed by a DAG belonging to a particular CPDAG may also be obtained from other DAG belonging to the same CPDAG.

SEM with latent variables has several additional identification conditions. First, there are at least three or more indicators for each latent variable. Second, each row $\boldsymbol{\Lambda}_{x}$ and $\boldsymbol{\Lambda}_{y}$ has one non-zero element. Third, each latent variable is scaled. Fourth, the value of $\boldsymbol{\Theta}_{\delta}$ is diagonal [12].

After the SEM identification process passes, the model parameter $\boldsymbol{\theta}$ can be estimated by finding the maximum value using likelihood procedure to find the smallest cost function value. The smaller the value of the cost function, the closer the model with the actual data [12].

$$
\begin{aligned}
& \widehat{\boldsymbol{\theta}}=\underset{\theta}{\operatorname{argmin}} F_{M L}(\boldsymbol{\theta}), \\
& F_{M L}(\boldsymbol{\theta})=\log \left|\sum(\boldsymbol{\theta})\right|+\operatorname{Tr}\left\{\boldsymbol{S} \boldsymbol{\Sigma}^{-1}(\boldsymbol{\theta})\right\}- \\
& \log |\boldsymbol{S}|-p .
\end{aligned}
$$

Where $p=r+q$ the number of observed variables, and $S$ is the covariance matrix $p \times p$ of observed variables.

\section{2) Non-dominated Sorting Genetic Algorithm II (NSGA-II) and Stability Selection}

The selected models are then processed with NSGAII. NSGA-II mimics the evolution cycle, by manipulating the best model from the previous selection. The best models of the first generation are manipulated (using operators called crossover and mutation methods) and are used to produce the second-generation model which is expected to be better than those of the first. This process is repeated until many generations. The crossover ensures variability of models for the next generation and the mutation is carried out to ensure that the model optimization will not get stuck in the local optima.

The model must be able to anticipate data fluctuations, this requires a stability selection process. Stability selection applies an iterative variable selection algorithm to a randomly drawn subset of half of the original data. The variable is selected when meets the predetermined threshold [12]. The best models from different subsets are collected, then combined and calculated using the concept of stability selection. The models are categorized based on their complexity, then the stability is calculated per pair of variables. Per pair of variables are calculated two types of stability. The first stability is all kinds of relationships, looking for its edge stability value, and the second by the causal path stability.

Final stage, drawing the plot per pair of the variables. The causal model based on the predetermined stability threshold (the stability threshold is generally 0.6) and the complexity threshold value using the BIC Score. Relevant structures are connected to each other based on relevant edges and their direction based on causal path stability. 
3) Stable Specification Search for Cross Sectional Data (S3C)

S3C looks for causal models based on score. S3C combines the concept of stability selection and multiobject optimization to find a stable and simple model structure for the observed variables. S3C method can be seen in Figure 2 [12].

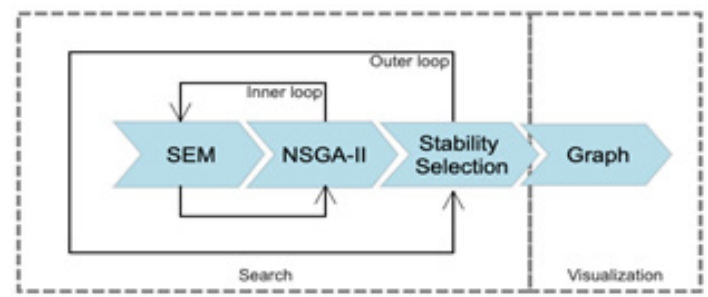

Figure 2. S3C method

SC3 consists of two phases, the optimal model search phase and the visualization phase. The search phase is an iterative procedure that requires an outer loop and an inner loop to find relevant edges and causal paths between two variables using SEM, NSGA-II and stability selection [12]. The relevant relationships that are displayed in the visualization phase are called causal models. The S3C pseudocode can be seen in Figure 3 [12].

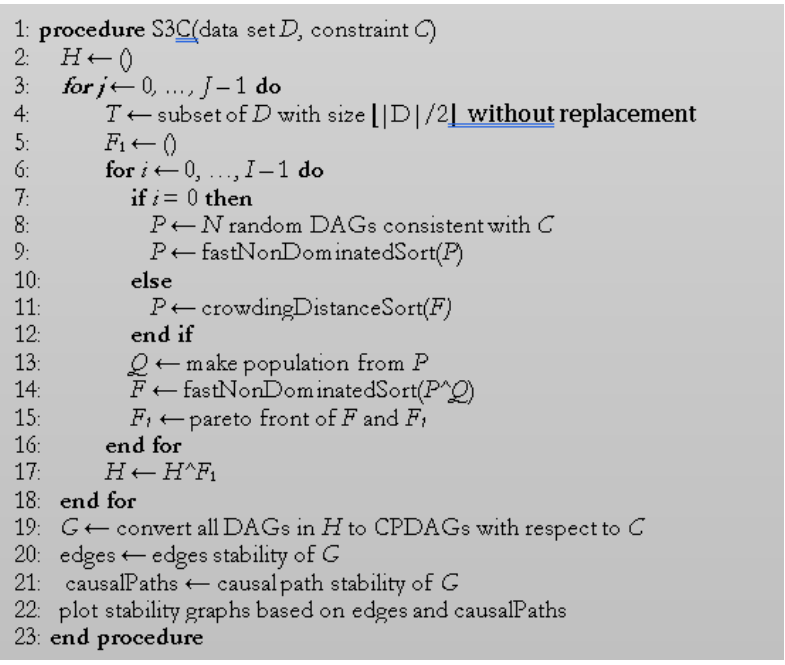

Figure 3. The pseudocode of S3C

The S3C procedure is divided into an inner loop and an outer loop. The inner loop used to find the pareto front with the NSGA-II implementation, while the outer loop created a sample from a subset of data. Pareto fronts were converted into CPDAG which was used to calculate the edge and causal path stability graphs.

Lines 6-16 interpreted an inner loop begins by randomly generating a population $P$ of size $N$ or using crowding distance sorting to get a previous population (Lines 7-12). A binary vector $\{0,1\}$ is a representation of the model, and denoted by some arc $X \rightarrow Y$. A new population of $Q$ is the result of $P$ manipulation using binary tournament selection, one-point crossover, and one-bit flip mutation. The best model from the selection placed in a mating pool $M_{\text {pool }}$ with selection scheme of taking the $N$ model twice from $P$. Two models from $M_{\text {pool }}$ are taken by one-point crossover and after the crossover point, data is swapped in the middle. Mutation of one-bit flip flips each bit according to a predetermined rate. The combination of $P$ and $Q$ using fast non-dominated sorting in Line 14 resulted a set of model fronts $F$. The Pareto front in $F_{1}$ updated by Line 15 .

Lines 3-18 interpreted an outer loop begins by randomly samples from $D$ to a subset $T$ with size $[|\mathrm{D}| / 2\rfloor$ (Line 4), Lines 6-16 run the inner loop with $I$ times to get a Pareto front, Line 17 places it in $H$. $H$ contains $J$ Pareto fronts after $J$ iterations is done.

$J$ Pareto fronts in $H$ converts DAGs into CPDAG (Lines 19-22) and then computes the edge and causal path stability graphs. The main output of S3C is the stability graphs which visualizes as a graph with nodes and edges [12].

\section{4) Stable Specification Search for Cross Sectional Data for Latent Variables (S3C-Latent)}

S3C-Latent was extended from S3C. The difference between S3C and S3C-Latent, S3C uses observed variables while S3C-Latent uses latent/unobserved variables. Pseudocode S3C-Latent was developed from S3C for computing latent variables. The S3C-Latent pseudocode can be seen in Figure 4 [12].

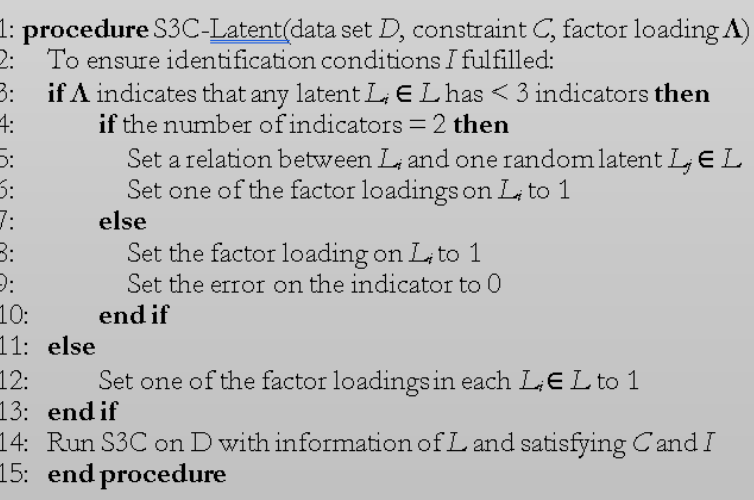

Figure 4. The pseudocode of S3C-latent

$D$ is the data set, $L$ is a set of $n$ latent variables, $\boldsymbol{\Lambda}$ is a matrix of factor loadings, and $C$ is a prior knowledge. Line 3 to confirm whether there is a latent variable $L_{i} \in$ $L$ which has less than 3 indicators. If found, then for each $L_{i}$, Line 4 will be executed or vice versa Line 12 will be executed. Line 4 checks the number of indicators $L_{i}$ is 2 or 1. If a case of 2 indicators is found, SC3-Latent establishes the relationship of the latent variable $L_{i}$ and random latent variable $L_{j} \in L$ (relates the latent variable $L_{i}$ to $L_{j}$, where $L_{i}$ can be cause or effect), and set one of the loading factors to 1 (Lines 5 and 6). If the indicator is 1, S3C-Latent will set 
the loading factor $L_{i}$ to 1 and set the error on the indicator to 0 (Lines 8 and 9 ). When all latent variables have at least 3 indicators then Line 12 exists. Line 14 runs S3C on the data set $(D)$ with the latent variable information from $L$, and satisfies any constraint in $C$ and the model identification conditions in I. S3C-Latent ensures that all SEMs that are generated and refined are compatible with the previous specified in $C$ by meeting constrains in $C$ (if any).

a. Evaluation

The model obtained in this study will be evaluated by experts in related field such as oncology nurses. The evaluation process uses a questionnaire. The evaluation will be conducted by online survey.

b. Dissemination

The final stage of this study aims to apply the causal model into an interactive website based. The application built with a shiny package in $\mathrm{R}$. The application is used to disseminate the model to a wider realm, especially for medical personnel who need information related to body image in patients with cancer.

\section{Results}

The computation stage begins with determining the parameter settings. The parameters in this study are the subset parameter $(S)$, the number of iterations $(I)$, the number of models evaluated $(P)$, the crossover probability $(C)$, and the mutation probability $(M)$. This study uses the amount of data $\mathrm{n}=199$ with the parameters were set as follows: $S=150, I=50, P=130, C=0.45, M=0.01$. Furthermore, added constraints, set gender and age did not cause body image factors in patients with cancer as constraints. Stability graph can be seen in Figure 5.

The stability graph consists of three dotted lines in blue, green, and red. The blue line (edge stability) depicts the relationship between pairs of variables regardless of direction, while the green and red lines represent the stability of the causal path with one length or any length that describes the causal relationship from one variable to another [12]. Based on stability graphs, behavior factors influenced cognitive factors and duration of illness. Gender has causal relations with affective, behavior, cognitive factors, and duration of illness. Age has causal relations with affective, cognitive factors, and duration of illness. The results also showed that affective associated with behavior, cognitive factors, duration of illness, and cognitive associated with duration of illness.

S3C-Latent is an exploratory score-based causal method that uses multi-objective optimization and stability selection to find robust causal relations (stable and simple) among latent variables in a structural model. The search for stable and parsimonious structural models used two thresholds. The first threshold was the boundary of selection probability $\pi_{\text {sel }}$, in this research used $\pi_{\text {sel }}=$ 0.6 [21], it means that all causal relationships with edge stability or causal path stability that exceed this value is considered stable. The second threshold was the boundary of complexity $\pi_{\text {bic }}$ that used to control overfitting [12], in this research used $\pi_{\text {bic }}=12$, it means that all causal relationships with edge stability or causal path stability lower than $\pi_{\text {bic }}$ are considered parsimonious.
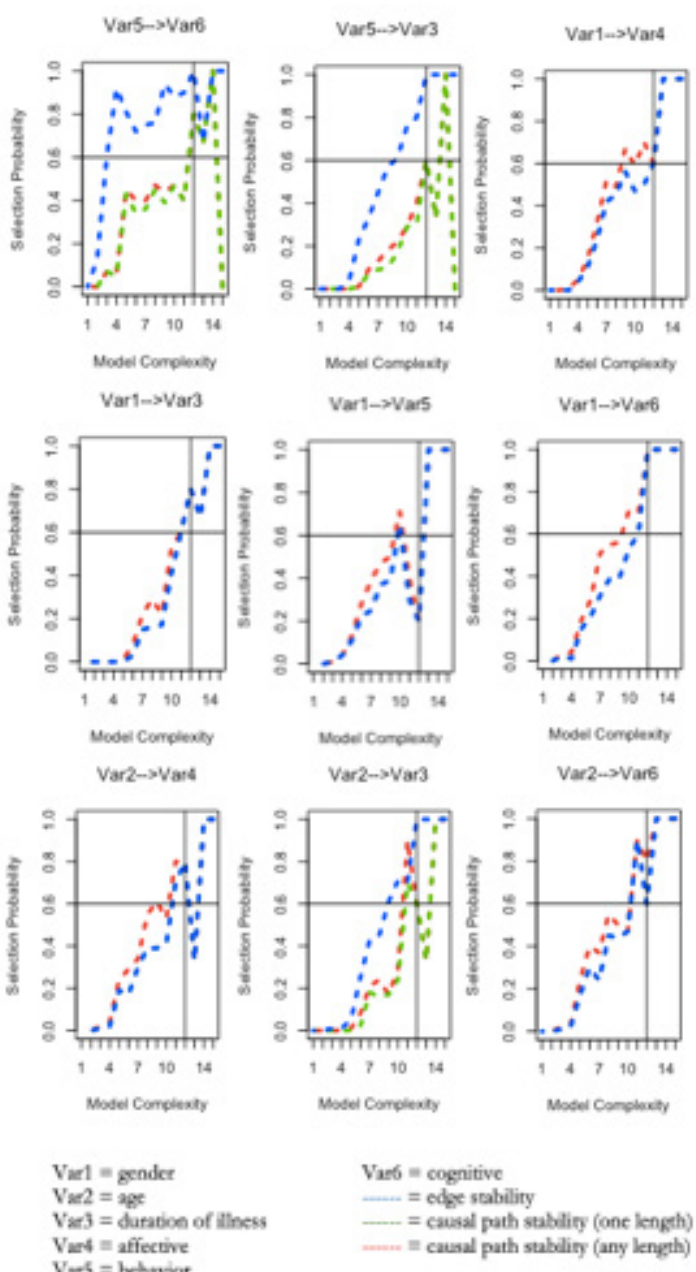

Vers affective

Figure 5. Stability Graph

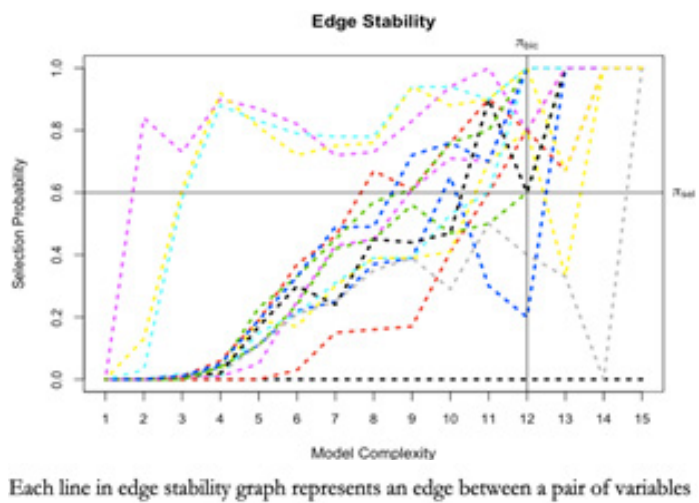

Figure 6. Edge Stability Graph 


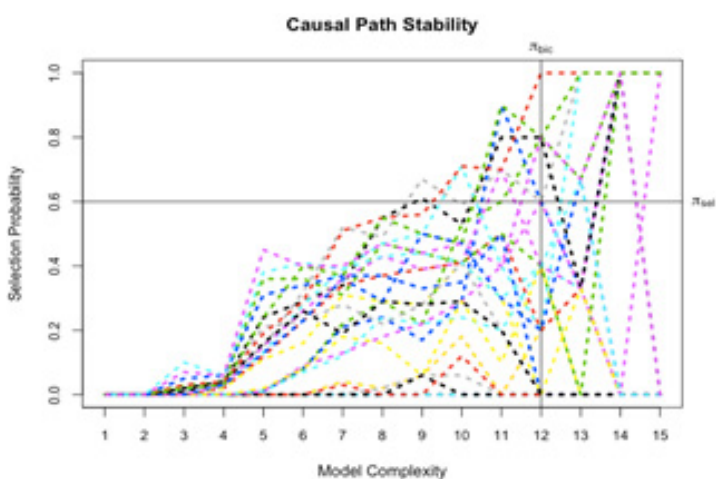

Each line in causal path stability graph represents a causal path with any length from a variable to another variable

Figure 7. Causal Path Stability Graph

Based in Figure 6 and 7, the edge stability and causal path stability graphs used $\pi$ sel $=0.6$ and $\pi$ bic $=12$. The edge stability graph showed there were 13 relevant edges on the top-left area. Based on causal path stability graph showed that there were nine relevant causal paths on the top-left area of the causal path stability graph.

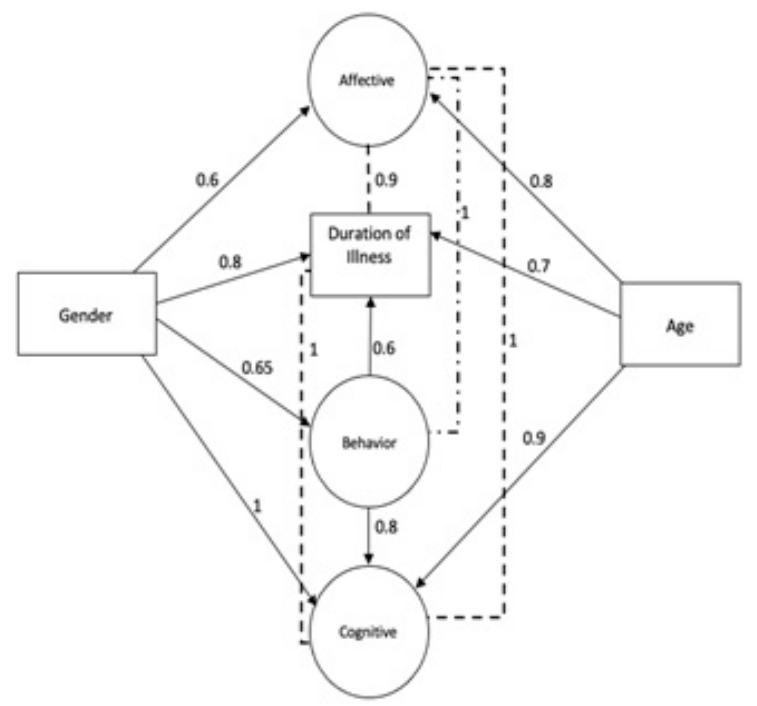

Figure 8. Causal model of body image patients with cancer estimated by S3C-latent algorithm

Causal modeling of body image factors in patients with cancer showed in Figure 8. There are causal relationships between behavior with cognitive factors and duration of illness with reliability scores of 0.8 and 0.6. The causal relations between gender and affective, duration of illness, behavior, cognitive factors with reliability scores of $0.6,0.8,0.65$, and 1 , respectively. Age relations with affective, duration of illness, and cognitive with reliability scores of $0.8,0.7$, and 0.9 , respectively. The results also show that affective is associated with behavior factors, cognitive factors, and duration of illness with reliability scores of 1,1 , and 0.9 , respectively. Cognitive factors and duration of illness are associated with reliability score of 1 .

Based on the modeling results obtained, two kinds of relation, causal relationship, and association. All causal relationships are associational, but not all associational relationships are causal, other than that correlation is not the same as causal [22]. Association is an improvement of correlation relationship.

The next stage, we implemented the results into the R Shiny App. R Shiny framework is a package from RStudio to build interactive web application with $\mathrm{R}$. The application displays information about the results of causal modeling of the body image factors in patients with cancer. The website is designed to display an explanation of the data, method, graphs, visualizations, and treatment recommendations, see Figure 9.

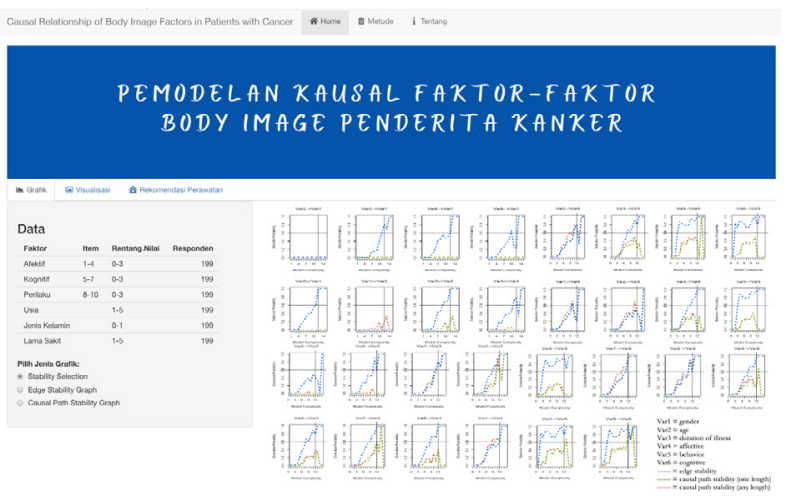

Figure 9. Graphs menu

\section{Discussion}

Based on the results obtained, there is a causal relationship between behavior and cognitive with a reliability score of 0.8 . This result in line with research [23] that nurses providing caring behavior to patients, the patients will be motivated, this is commonly called a cognitive process. Caring behavior by nurses can be a form of social support that can increase the patient's life expectancy.

The causal relationship between behavior and duration of illness with reliability score of 0.6. This research [24] found that wound healing after surgery and injury recovery are necessary for the patient. A poor wound healing process increases the risk of wound complications and infection, prolongs hospital stay, creates discomfort, and hinders daily activities. Psychological stress and other behavioral factors can affect the wound healing process.

The causal relationships between gender with affective and cognitive with reliability scores of 0.6 and 1, respectively in line with this research [25] that women are more mentally emotional than men. Women diagnosed with cervical cancer face many difficulties in accepting the fact that they are diagnosed with cancer. Their anxiety increased when imagining life changes and the side effects of treatment received. This would reduce a person's cognitive capacity in solving problems. Patients who experience anxiety close themselves off from other people. While those who can accept will be helped in the healing process. Encouragement and family support is one of the important factors in increasing women's awareness in preventing cervical cancer [26]. 
The causal relationships between gender with behavior and duration of illness with reliability scores of $0.65,0.8$, respectively has confirmed with this research [27] understanding that the disease is incurable and the advanced stage of the disease. To evaluate gender differences in patients' reports of discussions of life expectancy with oncology providers and its effect on differences in illness understanding. Methods Coping with Cancer 2 patients $(\mathrm{N}$ $=68$ that female patients with advanced cancer had a higher understanding of the disease than male patients. Female patients had more communication time with oncology providers about life expectancy than male patients. Efforts are needed to improve communication, especially for male patients in order to gain more understanding about their disease in order to get strong information to make medical decisions for patients at the end of their lives so that they can increase their life expectancy.

The causal relationship between age and affective with reliability score of 0.8 according to [28] found that women under the age of 40-60 years have higher body image dissatisfaction. Physical attractiveness in young women had a positive correlation with levels of happiness and self-esteem and had a negative correlation with levels of neurotics or anxiety. Higher bodies rate for young adult women associated with levels of self-satisfaction, respect from others, and sexual quality.

The causal relationship between age and duration of illness with reliability score of 0.7 in line with this study [29] that respondents between ages of 16-65 years had the most cancer $(78.4 \%)$. The older person has the lower body's immune level. Decreased body immunity will make it easier for cancer to multiply. Age influenced by an unhealthy lifestyle, irregular eating patterns, stress due to heavy workloads, smoking habits, and exposure to cigarette smoke when young can be the cause of cancer detected when old.

The causal relationship between age and cognitive with reliability score of 0.9 in line with the research [30] that cognition crucial for support functional independence as we get older, this includes the ability to live independently, financial management, how to take the right medicine, and how to drive safely. Cognition provides an important role for humans to communicate effectively, including processing and integrating sensory information, and responding appropriately to others. Cognitive abilities often decline with age. Changes in cognition resulting from the normal aging process decrease performance of cognitive tasks that require rapid processing of decisionmaking, including measures of processing speed, working memory, and executive cognitive function.

The association relationships between affective with behavior and cognitive with reliability scores of 1 , 1, respectively has confirmed [31]perspective-taking is closely linked to human empathy, and like empathy, perspective-taking is commonly subdivided into cognitive and affective components. While the two components of empathy have been frequently compared, the differences between cognitive and affective perspective-taking have been under-investigated in the cognitive neuroscience literature to date. Here, we define cognitive perspectivetaking as the ability to infer an agent's thoughts or beliefs, and affective perspective-taking as the ability to infer an agent's feelings or emotions. In this paper, we review data from functional imaging studies in healthy adults as well as behavioral and structural imaging studies in patients with behavioral variant frontotemporal dementia in order to determine if there are distinct neural correlates for cognitive and affective perspective-taking. Data suggest that there are both shared and non-shared cognitive and anatomic substrates. For example, while both types of perspective-taking engage regions such as the temporoparietal junction, precuneus, and temporal poles, only affective perspective-taking engages regions within the limbic system and basal ganglia. Differences are also observed in prefrontal cortex: while affective perspectivetaking engages ventromedial prefrontal cortex, cognitive perspective-taking engages dorsomedial prefrontal cortex and dorsolateral prefrontal cortex (DLPFC that affective is the ability to draw conclusions from the emotions and feelings of others. Affective is closely related to cognitive empathy. Cognitive empathy is the ability to model the emotions of other agents. Affective empathy results from a combination of cognitive and emotional empathy. Cognitive responses relevant in the adaptation process, cognitive factors can affect an event that can cause stress, determine the coping to be used, emotional reactions, physiology, behavior, and social. Behavioral responses represent emotional and physiological responses as a result of cognitive analysis in dealing with stressful conditions [32].

The association relationship between affective and duration of illness with reliability score of 0.9 in line with [33], patient with low levels of optimism tend to be less able to withstand the negative effects of treatment and susceptible to anxiety and depression. Treatment of cancer patients is focused on physical health, so psychological health is often neglected. Psychological health as a main role in the healing process, such as patient optimism in undergoing treatment.

The association relationship between cognitive and duration of illness with reliability score of 1 in line with [34] evaluated them for in-hospital delirium, and assessed global cognition and executive function 3 and 12 months after discharge with the use of the Repeatable Battery for the Assessment of Neuropsychological Status (population age-adjusted mean $[ \pm S D]$ score, $100 \pm 15$, with lower values indicating worse global cognition that patients in medical and surgical ICUs had potential risk for long-term cognitive disability. At three and twelve months, a longer duration of delirium in hospital was associated with lower global cognition and executive function levels.

\section{Conclusion}

Causal modeling is currently commonly used in many fields such as bioinformatics, medicine, image processing, 
sports outcome prediction, risk analysis, and quantum non-locality research. We have conducted causal modeling of body image factors in patients with cancer using S3CLatent. The resulted model showed that there are causal relationships between behavior with cognitive factors and duration of illness. Gender has causal relationships with affective factors, illness duration, behavior, and cognitive factors. Age has causal relationships with affective factors, illness duration, and cognitive factors. Affective factors are associated with behavior, cognitive factors, illness duration, while cognitive factors are associated with illness duration.

\section{Reference}

[1] C. A. Wijaya and M. Muchtaridi, "Pengobatan Kanker Melalui Metode Gen Terapi," Farmaka, vol. 15, no. 1, pp. 53-68, 2017.

[2] P. Nova and E. N. Sumintarddja, "Peran BRIEF CBT Terhadap Tingkat Depresi dan Masalah Body Image Pasien Kanker Payudara Dewasa Muda," J. Ilm. Psikol. MANASA, vol. 5, no. 2, pp. 103-113, 2016.

[3] H. C. Melissant et al., "A systematic review of the measurement properties of the Body Image Scale (BIS) in cancer patients," Support. Care Cancer, vol. 26, no. 6, pp. 1715-1726, 2018, doi: $10.1007 / \mathrm{s} 00520-018-4145-x$.

[4] Sriwahyuningsih, Dahrianis, and M. Askar, "Faktor yang berhubungan dengan gangguan citra tubuh (body image ) pada pasien post pperasi mastektomi di RSUP dr. Wahidin," STIKES Nani Hasanuddin Makassar, vol. 1, no. 3, pp. 1-6, 2012.

[5] L. A. Rozika and N. Ramdhani, "Hubungan antara harga diri dan body image dengan online self-presentation pada pengguna instagram," Gadjah Mada J. Psychol., vol. 2, no. 3, p. 172, 2018, doi: 10.22146/gamajop.36941.

[6] G. K. Tiwari and S. Kumar, "Psychology and body image : a review," Shodh Prerak, no. January, 2015.

[7] P. Hopwood, I. Fletcher, A. Lee, and S. Al Ghazal, "A body image scale for use with cancer patients," Eur. J. Cancer, vol. 37, no. 2, pp. 189-197, 2001, doi: 10.1016/S0959-8049(00)00353-1.

[8] W. Luo, W. Wu, and Y. Zhu, "Learning Heterogeneity in Causal Inference Using Sufficient Dimension Reduction," J. Causal Inference, vol. 7, no. 1, 2019, doi: 10.1515/jci-2018-0015.

[9] E. Wolfe, R. W. Spekkens, and T. Fritz, "The Inflation Technique for Causal Inference with Latent Variables," J. Causal Inference, pp. 70-91, 2019, doi: 10.1515/jci-2017-0020.

[10] T. A. Glass, S. N. Goodman, M. A. Hernán, and J. M. Samet, "Causal inference in public health," Annu. Rev. Public Health, vol. 34, pp. 61-75, 2013, doi: 10.1146/annurevpublhealth-031811-124606.

[11] M. L. Petersen and M. J. Van Der Laan, "Causal models and learning from data: Integrating causal modeling and statistical estimation," Epidemiology, vol. 25, no. 3, pp. 418-426, 2014, doi: 10.1097/ EDE.0000000000000078.

[12] R. Rahmadi, "Finding stable causal structures from clinical data," Radboud Universiteit Nijmegen, 2019.

[13] Z.-P. Ai, X.-L. Gao, J.-F. Li, J.-R. Zhou, and Y.-F. $\mathrm{Wu}$, "Changing trends and influencing factors of the quality of life of chemotherapy patients with breast cancer," Chinese Nurs. Res., vol. 4, no. 1, pp. 18-23, 2017, doi: 10.1016/j.cnre.2017.03.006.

[14] D. E. Fingeret, M. C., Teo, I., \& Epner, "Managing body image difficulties of adult cancer patients: lessons from available research," Cancer, vol. 120, no. 5, pp. 633-641, 2014, doi: 10.1002/ cncr.28469. Managing.

[15] S. S. Yatmi Tri, Effendy Christantie, "Gambaran diri dan kualitas hidup pasien kanker payudara," Gadjah Mada, 2018.

[16] S. A. Bahrami, M., Mohamadirizi, M., Mohamadirizi, S., \& Hosseini, "Evaluation of body image in cancer patients and its association with clinical variables," J. Educ. Health Promot., vol. 6, no. 81, 2017, doi: 10.4103/jehp.jehp_4_15.

[17] J. M. Youngblut, "A consumer's guide to causal modeling: Part I," J. Pediatr. Nurs., vol. 9, no. 4, pp. 268-271, 1994

[18] J. M. Youngblut, "A consumer's guide to causal modeling: Part II," J. Pediatr. Nurs., vol. 9, no. 6, pp. 409-413, 1994, [Online]. Available: https://www.ncbi.nlm.nih.gov/pmc/articles/ PMC3624763/pdf/nihms412728.pdf.

[19] P. Judea, Causality: models, reasoning and inference. Cambridge: Cambridge University Press, 2000.

[20] D. M. Chickering, "Learning Equivalence Classes of Bayesian-Network Structures," J. Mach. Learn. Res., vol. 2, no. 3, pp. 445-498, 2002, doi: $10.1162 / 153244302760200696$

[21] N. Meinshausen and P. Bühlmann, "Stability selection," J. R. Stat. Soc. Ser. B Stat. Methodol., vol. 72, no. 4, pp. 417-473, 2010, doi: 10.1111/j.1467-9868.2010.00740.x.

[22] S. D. Stovitz, E. Verhagen, and I. Shrier, "Distinguishing between causal and non-causal associations: implications for sports medicine clinicians," Br. J. Sports Med., vol. 53, no. 7, pp. 398 LP - 399, Apr. 2019, doi: 10.1136/ bjsports-2017-098520.

[23] S. P. S. Sulisno Madya, "Artikel asli," Media Med. Muda, vol. 1, no. Januari-April, pp. 7-12, 2016, 
[Online]. Available: https://ejournal2.undip.ac.id/ index.php/mmm/article/viewFile/2545/1527.

[24] P. J. et al Gouin, "NIH Public Access," NIH Public Access, vol. 31, no. 1, pp. 81-93, 2011, doi: 10.1016/j.iac.2010.09.010.The.

[25] M. Ubando, "Gender differences in intimacy, emotional expressivity, and relationship satisfaction," Pepperdine J. Commun. Res., vol. 4, no. 13, pp. 19-29, 2016, [Online]. Available: http://digitalcommons.pepperdine.edu/ pjcr\%5Cnhttp://digitalcommons.pepperdine. edu/pjcr/vol4/iss1/13.

[26] D. Susilawati, "Hubungan Antara Dukungan Keluarga dengan Tingkat Kecemasan Penderita Kanker Serviks Paliatif," J. Keperawatan Indones., vol. 4, no. 2, pp. 87-99, 2013, [Online]. Available: http://ejournal.umm.ac.id/index.php/ keperawatan/issue/view/226/showToc.

[27] K. Fletcher et al., "Gender differences in the evolution of illness understanding among patients with advanced cancer," J. Support. Oncol., vol. 11, no. 3, pp. 126-132, 2013, doi: 10.12788/j. suponc.0007.

[28] A. Melliana, Menjelajah tubuh perempuan dan mitos kecantikan. Yogyakarta: LKiS Yogyakarta, 2006.

[29] N. Wardana and R. Ernawati, "Hubungan Usia dan Aktivitas Fisik dengan Jenis Kanker di Ruang Kemoterapi RSUD Abdul Wahab Sjahranie Samarinda," Borneo Student Res., no. 2018, pp. 159-165, 2019, [Online]. Available: http://journals.umkt.ac.id/index.php/bsr/article/ view/950.

[30] D. L. Murman, "The Impact of Age on Cognition," Semin. Hear., vol. 36, no. 3, pp. 111-121, 2015, doi: $10.1055 /$ s-0035-1555115.

[31] M. L. Healey and M. Grossman, "Cognitive and affective perspective-taking: Evidence for shared and dissociable anatomical substrates," Front. Neurol., vol. 9, no. JUN, pp. 1-8, 2018, doi: $10.3389 /$ fneur.2018.00491.

[32] S. Nyumirah, "Pengaruh Terapi Perilaku Kognitif Terhadap Kemampuan Interaksi Sosial Klien Isolasi Sosial di RSJ Dr. Amino Gondhohutomo Semarang," 2012.

[33] R. Saniatuzzulfa and S. Retnowati, "Program " Pasien PANDAI “ untuk Meningkatkan Optimisme Pasien Kanker," Gadjah Mada J. Prof. Psychol., vol. 1, no. 3, pp. 163-172, 2015.

[34] P. P. Pandharipande et al., "Long-term cognitive impairment after critical illness.," N. Engl. J. Med., vol. 369, no. 14, pp. 1306-1316, Oct. 2013, doi: 10.1056/NEJMoa1301372. 